\section{Go \\ DENTAL MEDICINE}

1) Department of Medical, Surgical and Health Sciences, School of Dentistry, University of Trieste, Trieste, Italy

2) Private Practice, Maniago, Italy

3) Private Practice, Beirut, Lebanon

4) Departments of Oral Medicine and Maxillofacial Radiology and Oral and Maxillofacial Surgery, Lebanese University, Faculty of Dental Medicine, Beirut, Lebanon

5) Department of Emergency Medicine, American University of Beirut Medical Center, Beirut, Lebanon
DOI: $10.15386 / \mathrm{mpr}-1914$

Manuscript received: 24.09 .2020

Received in revised form: 04.03.2021

Accepted: 24.03.2021

Address for correspondence:

abbass@abbass.org

This work is licensed under a Creative Commons Attribution-NonCommercialNoDerivatives 4.0 International License

\title{
Radiographic evaluation of non-syndromic third molar agenesis in two Mediterranean populations
}

Bachar Reda ${ }^{1}$, Federica Fantin ${ }^{2}$, Khetam Berro ${ }^{3}$, Ziad Noujeim ${ }^{4}$, Abbass El-Outa ${ }^{5}$

\begin{abstract}
Background and aims. Third molar agenesis is a common finding across the world. Many studies have assessed third molar agenesis in different ethnicities and populations. However, there are no such studies in the Italian and Lebanese populations. Our study aims to evaluate the prevalence of third molar agenesis and study the pattern and distribution of agenesis in between genders in Italian and Lebanese Mediterranean populations and compare these findings with other global and Mediterranean populations' studies.
\end{abstract}

Methods. Retrospective chart review was conducted based on the history and orthopantomograms of adolescents aged 12 to 21 years to assess the agenesis of third molars in a sample of Italian and Lebanese populations by two experienced dental surgeons twice within 1 month. Descriptive and comparative tests were used to analyze the patterns of ageneses and make comparisons between the two samples.

Results. $23.4 \%$ of the studied sample had at least one third molar agenesis; females were more likely to have two or more third molar agenesis than males, but neither sex predisposition for single third-molar agenesis was recorded. Both the Italian and Lebanese subgroups seemed to have similar results. The maxillary right third molar was the most common third molar to be absent. Two or more ageneses were more common than one third molar agenesis.

Conclusion. Our Mediterranean population results fall within the range reported in the literature and corroborate with the global average prevalence.

Keywords: Mediterranean population, panoramic radiography, third molar, dental agenesis

\section{Introduction}

Third molars (M3) are notorious for being teeth associated with pathological conditions. Such pathologies include impaction, ectopic eruption, hard and soft tissue pathologies, and agenesis, signs of $\mathrm{M} 3$-associated disease being estimated up to $47 \%$ in adults $[1,2]$.

The relationship of the third molar with the adjacent second molar is an additional concern for developing pathologies [3]. In fact, a very common culprit of such malposition is pericoronitis [4]. Several authors have attempted to evaluate the position of third molar impaction and the development of pericoronitis, with conflicting conclusions [5]. Another common condition is periodontal disease; from increased probing depth to increased flora associated with periodontal disease, potentiated by the difficulty for proper hygiene measures due to abnormal positioning, all increase periodontitis risk for the second molar [3]. Moreover, a recent systematic review reported lowcertainty evidence of the association between disease-free impacted M3 and second molar periodontitis [6]. Additionally, dental caries, odontogenic tumors, odontogenic cysts and even mandibular fractures may be associated 
with retained M3 [5]; the prevalence of cysts and tumors in association with $\mathrm{M} 3$ ranges between $0.8 \%$ to $6.2 \%$, and such risk increases especially with mandibular impacted M3 in older patients [7].

Management modalities of pathologies associated with third molars range from no-intervention and monitoring, to only managing emerging diseases, and M3 extraction. For pericoronitis, local hygiene measures may be enough, yet recurrent pericoronitis presents an indication for M3 extraction [8]. As with periodontal disease, little evidence exists in support of traditional periodontal therapy as it seems ineffective, probably due to the malpositioning of the M3s (impacted or not) and sub-optimal procedural accessibility [3]. Nevertheless, the most common management modality of pericoronitis, periodontal disease and other associated conditions is the removal of M3, prophylactically or within pathological settings [4]. Early removal is sometimes advocated to prevent the development of M3-associated disease in the future, with some even resort to germectomy, considering it surgically easier with less complication risk [4].

Nevertheless, to date, there is no definitive evidence that draws a clear line of indication to retain or prophylactically extract M3s. In fact, the dilemma to retain M3s or not is one of the most difficult clinical decisions faced by dentists [9]. Adversaries of prophylactic extraction of M3 base their reasons on the cost of the procedure as well as associated morbidity, in addition to the absence of evidence for benefits of systematic extraction [5]. The only available evidence from literature advises against the extraction of M3 to prevent crowding of anterior mandibular teeth [10]. Therefore, the decision to extract disease-free M3 mainly relies on benefit-risk basis and clinician judgment. In the event that M3s are retained, regular follow-ups are necessary to detect any pathological process early and treat before damage is caused [6].

Eventually, agenesis of M3 can be regarded as a "favorable pathology" among all dental and M3-associated diseases. Indeed, agenesis of one or more M3 is a common finding across different world populations. Several authors have inspected the agenesis of the M3. As a matter of fact, Carter and Worthington (2015) estimate that around a quarter of world population suffers from at least one third molar agenesis, while another quarter suffer from third molar impaction $[11,12]$.

From an evolutionary perspective, it is hypothesized that third molars will cease to exist in the human dentition in the future. Skulls of pre-historic humans have shown a much less third molar agenesis than it is currently common [12]. Therefore, recording the prevalence of third molar agenesis is important not only for epidemiological mapping, but also for following evolutionary trends across the globe and throughout time. In fact, many authors have inspected the prevalence of M3 agenesis in different populations [13]; however, to our knowledge, there is no data on third molar agenesis in Italian or Lebanese samples.

Accordingly, our study aims to evaluate the prevalence of M3 agenesis in a Mediterranean sample of Italian and Lebanese populations. Furthermore, we aim to study the inter-racial differences, gender predisposition and patterns of agenesis in our sample. Given the genetic nature of tooth agenesis and the historical mixing of Mediterranean peoples, we hypothesize that both samples, Italian and Lebanese, possess close epidemiological features of third molar agenesis.

\section{Methods}

In this cross-sectional retrospective study, 3272 medical/dental charts were reviewed for patients presented between August 2017 and August 2019 to two private dental clinics in Italy and two in Lebanon. Files of adolescents aged 12 to 21 were selected, and certain cases were exluded based on the following criteria:

1- History of any wisdom tooth extraction or germectomy

2- Presence of syndromic disorders, especially those associated with dental anomalies or chronic systemic disease

3- History of trauma or disease affecting facial development

4- Absence or presence of unclear or nonstandardized panoramic radiograph

5- Patients who refused to use their diagnostic or treatment details for research purpose

Finally, 282 patients were selected, and their respective orthopantomograms were inspected for inexistent third molar by 2 experienced dental surgeons; OPGs were re-evaluated after 1 month and findings were compared with previous inspection. Eventually, results were transferred into statistical software for subsequent analysis and study of agenesis pattern.

The starting age was set at 12 years where third molar germ would be radiologically discernible at such age. We have set the upper age limit at 21 years for two reasons: (1) this study is conducted in an adolescent population; (2) in such a young age range, patients are less likely to fail to remember prior third molar extraction and hence lead to more precise history.

All patients whose OPGs were included had a signed informed consents that stated their radiographs may be used for scientific research in an unidentified manner.

Data entry and statistical analyses were conducted using IBM SPSS Statistics for Windows, version 24 (IBM Corp., Armonk, N.Y., USA). Descriptive statistics were presented as frequencies for categorical variables and mean \pm standard deviation for age. Normality of distribution of variables was assessed using graphical plots and verified with one-sample Kolmogorov-Smirnov test. Fischer's exact test, chi-square test and one-sample binomial test were done to evaluate differences within and between 
categorical variables. Kruskal-Wallis test and MannWhitney tests were used for hypotheses testing as nonparametric tests. A confidence interval of $95 \%$ was used, and level of significance was set below $\mathrm{p}=0.05$.

\section{Results}

As stated before, age ranged from 12 to 21 years old with a mean of 15.8 years \pm 2.8 . Out of the 282 studied patient files, $148(52.5 \%)$ were females and $127(45 \%)$ were males. Concerning nationality, the sample was almost equally divided into 145 (51.4\%) Italian patients and 137 (48.6\%) Lebanese.

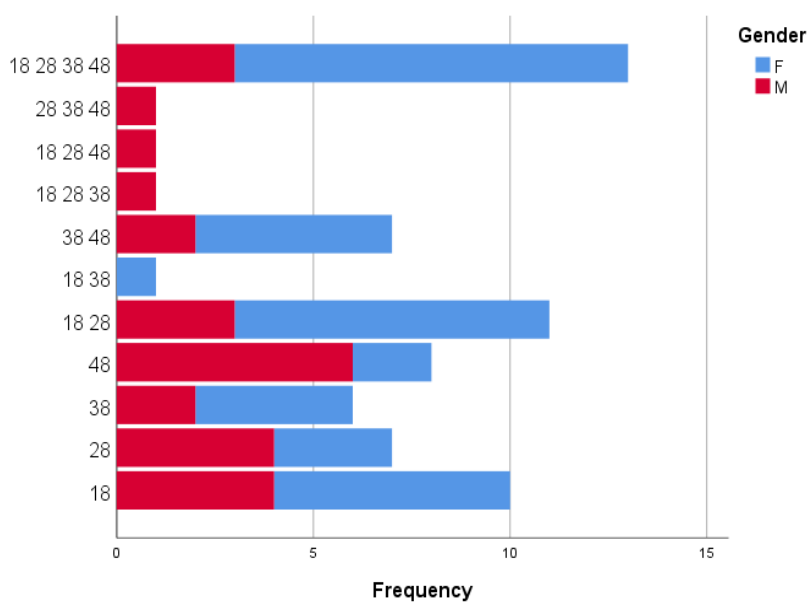

Figure 1. Sex distribution per each agenesis pattern (single, double, triple and total third molar agenesis). F: female; M: male; tooth numbering using FDI system.
Third molar agenesis was apparent in 66 cases out of the 282 studied sample. Consequently, a prevalence of $23.4 \%$ was recorded. Females were slightly more affected than males with a ratio of $3: 2$, but this difference was not statistically significant $(\mathrm{p}=0.176)$ (Figure 1$)$. Cases were divided equally between Italian and Lebanese subjects with a ratio of 1 to 1 .

Concerning agenesis patterns, $31 \quad(47.0 \%$ of ageneses $-11.0 \%$ of whole sample) patients showed single third-molar agenesis, while 35 (53.0\%) showed multiple third-molar agenesis.

Single agenesis of third molars had no gender predisposition nor nationality predilection in our studied sample, and constituted $11.0 \%$ of all the studies samples. The maxillary right third molar was the most common wisdom tooth to be absent, and the mandibular left one was the least commonly absent.

On the contrary, multiple third-molar agenesis was significantly higher in females than in males with a predisposition of 7:3; however, nationality difference was insignificant. Regarding the pattern of multiple agenesis, total quadrilateral third-molar agenesis was the most common pattern with a prevalence of $19.7 \%$ of all ageneses (4.6\% within all of the studied sample). The second most common multiple agenesis pattern was bilateral maxillary third-molar agenesis; in other words, two third-molar teeth agenesis existed in $28.8 \%$ of cases, and the least was for three third-molar teeth agenesis (4.5\%). Surprisingly, no cases of combined agenesis of $38-48,28-38,28-48,18-48$, or $18-38-48$ were recorded (Table I).

Table I. Distribution of agenesis pattern with gender and nationality differences. Tooth numbering using FDI system; single: one third molar agenesis; multiple: two or more third molar ageneses; F: female; M: male; I: Italian; L: Lebanese.

\begin{tabular}{|c|c|c|c|c|c|c|}
\hline & \multirow{2}{*}{ Frequency } & \multirow{2}{*}{ Percent (\%) } & \multicolumn{2}{|c|}{ Gender } & \multicolumn{2}{|c|}{ Nationality } \\
\hline & & & Ratio F:M & $p$ & Ratio I:L & $p$ \\
\hline No agenesis & 216 & 76.6 & & & & \\
\hline Agenesis & 66 & 23.4 & $3: 2$ & 0.176 & $1: 1$ & 0.712 \\
\hline \multicolumn{7}{|c|}{ Agenesis Patterns (Total: $66 / 100 \%$ ) } \\
\hline Single (tooth number) & 31 & 47.0 & $1: 1$ & 1.000 & $2: 3$ & 0.281 \\
\hline 18 & 10 & 15.2 & & & & \\
\hline 28 & 7 & 10.6 & & & & \\
\hline 38 & 6 & 9.1 & & & & \\
\hline 48 & 8 & 12.1 & & & & \\
\hline Multiple (teeth numbers) & 35 & 53.0 & $7: 3$ & 0.043 & $1: 1$ & 0.735 \\
\hline 1828 & 11 & 16.7 & & & & \\
\hline 1838 & 1 & 1.5 & & & & \\
\hline 3848 & 7 & 10.6 & & & & \\
\hline 182838 & 1 & 1.5 & & & & \\
\hline 182848 & 1 & 1.5 & & & & \\
\hline 283848 & 1 & 1.5 & & & & \\
\hline 18283848 & 13 & 19.7 & & & & \\
\hline Total & 282 & 100 & & & & \\
\hline
\end{tabular}




\section{Discussion}

This study reports epidemiological features of third molar agenesis in Italian and Lebanese samples. Our results highlight the similar prevalence and patterns of such condition in both samples, with a relatively-high agenesis rate of $23.4 \%$. Furthermore, gender predilection was not evident except in case of multiple M3 ageneses, where females had more such ageneses than males. Our study encompassed adolescents starting from 12 years of age. Such lower limit was chosen based on the fact that third molar germ formation starts at 7 to 10 years, and, therefore, crown calcification is evident by 12 years on radiographic imaging [14-16].

Several authors studied the prevalence of third molar agenesis in different ethnicities and populations. The presence of clear and reliable studies evaluating third molar agenesis will allow regular monitoring of the evolutionary regression of third molar presence.

Other authors have evaluated the prevalence of third molar agenesis in other Mediterranean peoples. Goyal et al. (2016) examined 700 orthopantomograms for third molar agenesis in a Sriganganagar population [17]; they found the prevalence rate to be $34.1 \%$, slightly higher than ours. They reported an almost identical result of total thirdmolar agenesis ( $4.7 \%$ compared to $4.6 \%$ in our study), and a slightly higher single third-molar agenesis prevalence of $14.4 \%$, compared to $11 \%$ in our study. Hattab et al. (1995) studied the prevalence in a Jordanian sample of 232 individuals and reported a high prevalence of $27 \%$, slightly more than that found by us [18]. In the Turkish population, Celikoglu and Kamak (2012) and Kazanci et al. (2010) reported a prevalence of third-molar agenesis of $22.7 \%$ and $23.8 \%$ respectively, while Komerik et al. (2014) reported a much higher prevalence of $37 \%[19,20]$. Garcia-Hernandez and Rodriguez in 2009 evaluated the prevalence of thirdmolar agenesis in a Greek population and reported it was $19.3 \%$ [11]. In a Libyan sample, Byahatti and Ingafou, (2012) reported a low prevalence rate of $6.5 \%$ [21].

A systematic review in 2015 was conducted by Carter and Worthington which evaluated studies on demographic predictors of third molar agenesis [11]. The authors calculated the global mean of third molar agenesis, which turned out to be around $22.6 \%$, which is relatively equal to that reported in our study $(23.4 \%)$. Global gender distribution turned out to be almost equal, with very slight female predominance. Conversely, the study reported higher incidence of single third molar agenesis in comparison with multiple ageneses, unlike in our study where more than 1 third molar agenesis was more common than single third molar agenesis.

To our knowledge, this is the first study to describe third molar agenesis in Italian and Lebanese populations. In the Italian population, authors such as Gracco et al. (2017) and Vona et al. (1993) evaluated hypodontia but excluded third molar agenesis [22,23]. In the Lebanese population, there are no studies to date on such condition. Such studies are essential for mapping epidemiological features of M3 agenesis, which are essential for future research to understand such agenesis; in addition, through these studies, future meta-analyses would be able to establish demographic predictors of such condition, and contribute to the evolutionary prediction of M3 persistence in the future.

\section{Conclusion}

Third molar agenesis seems a common finding in different populations across the globe. However, due to differences in genetics and ethnicities, there exists quite high variations in reported prevalence and pattern among world populations. Our study showed that the prevalence and pattern of third molar agenesis in Italian and Lebanese samples fall in accordance with world prevalence range, in addition to other Mediterranean populations. Future largescale multicenter studies are warranted in several areas of Italy and Lebanon to confirm these epidemiological findings.

\section{References}

1. Deliverska EG, Petkova M. Complications after extraction of impacted third molars - literature review. J of IMAB. 2016;22:1202-1211.

2. Ventä I, Vehkalahti MM, Huumonen S, Suominen AL. Signs of disease occur in the majority of third molars in an adult population. Int J Oral Maxillofac Surg. 2017;46:1635-1640.

3. Tian Y, Sun L, Qu H, Yang Y, Chen F. Removal of nonimpacted third molars alters the periodontal condition of their neighbors clinically, immunologically, and microbiologically. Int J Oral Sci. 2021;13:5.

4. Camargo IB, Sobrinho JB, Andrade ES, Van Sickels JE. Correlational study of impacted and non-functional lower third molar position with occurrence of pathologies. Prog Orthod. 2016;17:26.

5. Campbell JH. Pathology associated with the third molar. Oral Maxillofac Surg Clin North Am. 2013;25:1-10, v.

6. Ghaeminia H, Perry J, Nienhuijs ME, Toedtling V, Tummers M, Hoppenreijs TJ, et al. Surgical removal versus retention for the management of asymptomatic diseasefree impacted wisdom teeth. Cochrane Database Syst Rev. 2020;(8):CD003879.

7. Shin SM, Choi EJ, Moon SY. Prevalence of pathologies related to impacted mandibular third molars. Springerplus. 2016;5:915.

8. Adeyemo WL. Do pathologies associated with impacted lower third molars justify prophylactic removal? A critical review of the literature. Oral Surg Oral Med Oral Pathol Oral Radiol Endod. 2006;102:448-452.

9. McCoy JM. Complications of retention: pathology associated with retained third molars. Atlas Oral Maxillofac Surg Clin North Am. 2012;20:177-195. 
10. Costa MG, Pazzini CA, Pantuzo MC, Jorge ML, Marques LS. Is there justification for prophylactic extraction of third molars? A systematic review. Braz Oral Res. 2013;27:183188.

11. Carter K, Worthington S. Morphologic and Demographic Predictors of Third Molar Agenesis: A Systematic Review and Meta-analysis. J Dent Res. 2015;94:886-894.

12. Carter $\mathrm{K}$ The evolution of third molar agenesis and impaction. [Doctoral dissertation], Harvard University, Graduate School of Arts \& Sciences, 2016, 171 p.

13. Rakhshan V, Rakhshan H. Meta-analysis and systematic review of the number of non-syndromic congenitally missing permanent teeth per affected individual and its influencing factors. Eur J Orthod. 2016;38:170-177.

14. Kaur B, Sheikh S, Pallagatti S. Radiographic assessment of agenesis of third molars and para-radicular third molar radiolucencies in population of age group 18-25 years oldA radiographic survey. Arch Oral Res. 2012;8:13-18.

15. Liversidge HM, Peariasamy K, Folayan MO, Adeniyi AO, Ngom PI, Mikami Y, et al. A radiographic study of the mandibular third molar root development in different ethnic groups. J Forensic Odontostomatol. 2017;35:97-108.

16. Jung YH, Cho BH. Radiographic evaluation of third molar development in 6- to 24-year-olds. Imaging Sci Dent. 2014;44:185-191.
17. Goyal S, Verma P, Raj SS. Radiographic Evaluation of the Status of Third Molars in Sriganganagar Population - A Digital Panoramic Study. Malays J Med Sci. 2016;23:103112 .

18. Hattab FN, Rawashdeh MA, Fahmy MS. Impaction status of third molars in Jordanian students. Oral Surg Oral Med Oral Pathol Oral Radiol Endod. 1995;79:24-29.

19. Celikoglu M, Kamak H. Patterns of third-molar agenesis in an orthodontic patient population with different skeletal malocclusions. Angle Orthod. 2012;82:165-169.

20. Kazanci F, Celikoglu M, Miloglu O, Oktay H. Third-molar agenesis among patients from the East Anatolian Region of Turkey. J Contemp Dent Pract. 2010;11:E033-E040.

21. Byahatti S, Ingafou MS. Prevalence of eruption status of third molars in Libyan students. Dent Res J (Isfahan). 2012;9:152-157.

22. Polder BJ, Van't Hof MA, Van der Linden FP, KuijpersJagtman AM. A meta-analysis of the prevalence of dental agenesis of permanent teeth. Community Dent Oral Epidemiol. 2004;32:217-226.

23. Gracco ALT, Zanatta S, Forin Valvecchi F, Bignotti D, Perri A, Baciliero F. Prevalence of dental agenesis in a sample of Italian orthodontic patients: an epidemiological study. Prog Orthod. 2017;18:33. 